https://doi.org/10.15407/ujpe63.9.824

KULDEEP KUMAR, ${ }^{1}$ P. ARUN ${ }^{2}$

${ }^{1}$ Department of Physics, S.G.T.B. Khalsa College, University of Delhi

(e-mail: kuldeep@sgtbkhalsa.du.ac.in)

2 Material Science Research Lab, S.G.T.B. Khalsa College, University of Delhi

(e-mail: arunp92@sgtbkhalsa.du.ac.in)

\title{
SPR IN CESIUM HALIDE THIN FILMS DUE TO EMBEDDED ELLIPTIC CESIUM METAL NANO-PARTICLES
}

\begin{abstract}
Cesium nanorods embedded in cesium halides ( $\mathrm{CsCl}$, CsBr, and CsI) show surface plasmon resonance $(S P R)$ absorption peaks. The size and shape of these cesium nanorods in the cesium halide matrix evolve with time, which gives some uncontrollable data for comparing with the theory. The theory used here was developed by R. Gans. It leads to the good match between experiment and theory for $C s-C s$ halide nanocomposites.
\end{abstract}

Ke ywords: alkali halides, thin films, X-ray diffraction, UV-visible spectroscopy.

\section{Introduction}

Interest in alkali halides $(\mathrm{AH})$ such as $\mathrm{CsCl}, \mathrm{CsBr}$, and CsI has been renewed due to their novel optical properties and possible applications in devices [1], especially in optical wave guides [2]. Initial interest in $\mathrm{AH}$ was due to a variation in their energy band structure due to changes induced in their lattice constants [3]. Alkali halides are a photon-absorbing material in the X-ray and ultraviolet regions due to their large band-gaps $[4,5]$. However, when the compressive pressures are applied to unit cells, their lattice constants decrease, and they start to show the metallic behavior. Thin layers of $\mathrm{AH}$ have been used as protective layers of a photo-cathode and an electron source $[6,7]$. In addition, $\mathrm{AH}$ have gained popularity in detector and optoelectronic applications due to their excellent quantum efficiency [8]. Cesium Halides have also been used as water soluble photoresists in the IC fabrication process $[9,10]$. The recent report on the natural ageing process has again brought the spotlight on $\mathrm{AH}$ [11]. It was observed that $F$-centers $/ F_{2}$ centers or defects are formed due to the halide atoms moving out of their lattice positions under the heat treatment [12-14], which leads to the clustering of Cs atoms. This causes the strong absorption in the UV-visible spectral region. Scott [15] also showed that the precipitation volume of metal clusters formed in alkali halides depends on

(C) KULDEEP KUMAR, P. ARUN, 2018 the annealing time. This strong absorption observed has been ascribed to Surface Plasmon Resonance (SPR) [16].

Metallic nanoparticles (such as cesium ones) embedded in a dielectric matrix (such as cesium halides) exhibit the interesting optical properties due to the collective resonant oscillations of conduction electrons. These collective oscillations on the metallic surface are called Surface Plasmon Resonance (SPR) [17]. The optical absorption spectra of metallic nanoparticles can be explained by the classical Mie theory [18] provided the shape of the nanoparticles are spherical. In the case where the shapes of nanoparticles are deformed, i.e. they are not spherical in shape and have taken an ellipsoidal shape (prolate/oblate), then the Gans model is used. R. Gans [19] had extended Mie's work for non-spherical particles. The theory predicts the splitting of an SPR peak into the longitudinal mode along the major axis and the transversal mode perpendicular to the major axis [20]. The details of calculation of the extinction coefficient $\sigma_{\text {ext }}$ within Gans' model have been given by Link et al. [21]

In the present work, we report the results of theoretical calculations made for the extinction coefficients of cesium metal nanorods in $\mathrm{CsCl}, \mathrm{CsBr}$, and CsI matrix using Gans' model. These calculations were then compare with the experimental results reported earlier in $[12-14]$. The factors known to influence the SPR peak position are the size of a metal nanoparticle, its dielectric constant (i), par-

ISSN 2071-0194. Ukr. J. Phys. 2018. Vol. 63, No. 9 
ticle shape, and (ii) the surrounding media via its dielectric constant. We shall investigate factors (i) \& (ii) in cesium-cesium halide nanocomposite films, i.e. various graphs have been generated for cesium nanorods with varying sizes in three different cesium halide matrices surrounding backgrounds $(\mathrm{CsCl}$, CsBr, \& CsI), by using the Gans' model. The dielectric constant $\epsilon$ for the cesium metal required as an input parameter for calculations within Gans' model was taken from the work by Smith [22].

\section{Results and Discussion}

\subsection{Dependence on the aspect ratio}

As was discussed, the nature of the SPR peak and its position strongly depend on the shape of a metal nanocluster. A sphere due to its symmetry would result in a single SPR peak. However, in a nonspherical shaped metal nanocluster like a nanorod, the Coulombic restoring force on the electron cloud would be different in different directions due to the varying surface curvatures (Fig. $1, a$ ). Hence, depending on whether the excitation radiation is falling perpendicularly to or in parallel to the axis of a nanorod (hence, seeing two different curvatures), two SPR peaks are obtained, the transverse and longitudinal modes, respectively. The asymmetry in the nanorod relative to a sphere is given as the aspect ratio (aspect ratio is the ratio of the minor axis to the major one, see Fig. 1, a). In this paper, we have carried out simulations for aspect ratios varying from 0.1 to 0.9 . Figure $1, b$ shows the two peaks for cesium metal nanorods with an aspect ratio of 0.4 in a cesium bromide matrix. The clearly resolved transverse and longitudinal modes in the visible and IR region of the spectrum, respectively, can be seen. The experimental results for cesium-cesium bromide nanocomposites with nanorods of $\approx 0.4$ aspect ratio have been presented together with the theoretical results. The match between them in the visible region (experimental result was obtained, by using UV-visible spectroscopy for $300 \leq \lambda \leq 900)$ is quite good. As explained above, the SPR peak position (or rather the maxima of the extinction coefficient $\sigma_{\text {ext }}$ ) becomes very sensitive to the aspect ratio of the nanoparticle. In fact, a small variation in the aspect ratio results in a huge shift in the SPR peak position.

Figure 2 was drawn from numerous theoretical simulations made for nanorods with different aspect
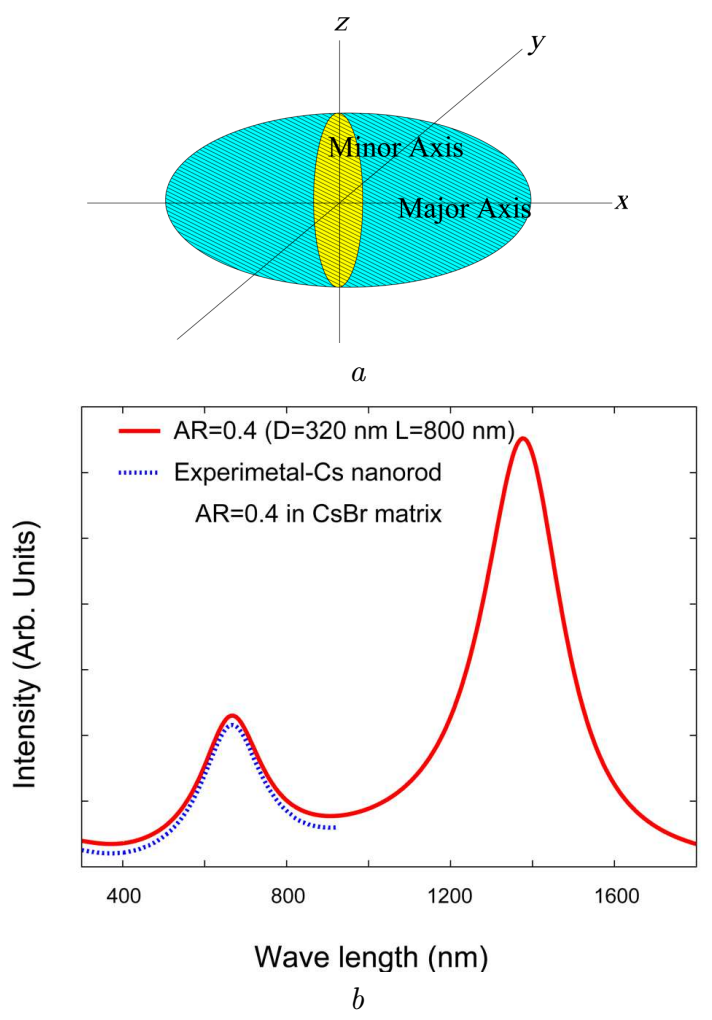

Fig. 1. Illustration of the geometrical shapes of the nanoparticle (ellipsoid) $(a)$. The simulation shows SPR peaks of due to non-spherical cesium metal clusters in a cesium bromide medium (i.e. $\mathrm{AR} \neq 1)(b)$. The theoretical values agree well with the experimental curve
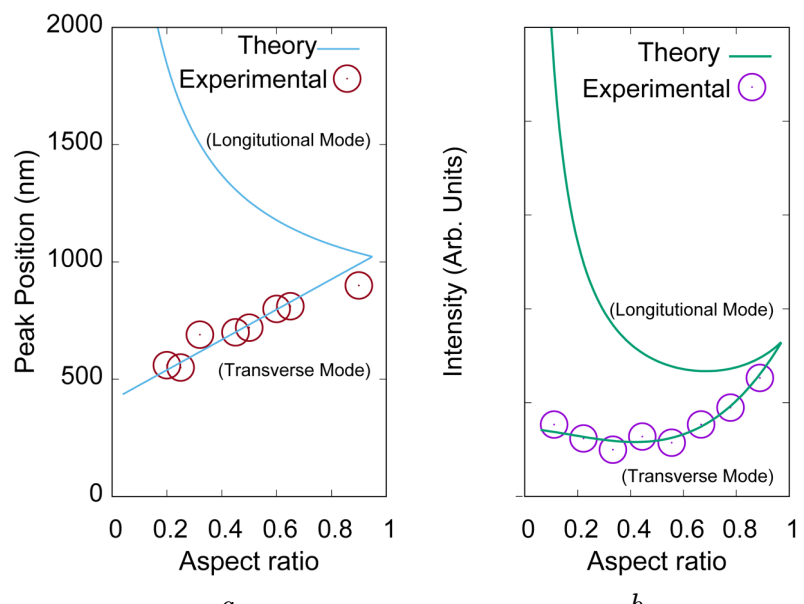

Fig. 2. Simulation shows variations in the SPR peak position (a) and the dependence of the peak intensity on the aspect ratio (b). Curves were generated for the fixed metal nanocluster size and surrounding medium 


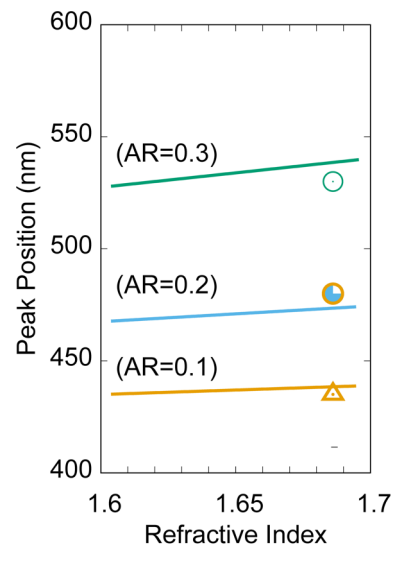

$a$

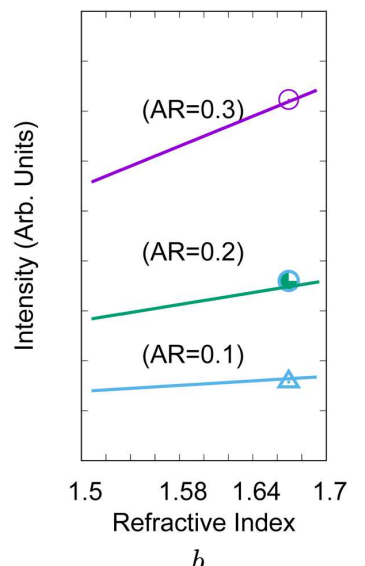

$b$

Fig. 3. Simulation showsa a family of curves (different aspect ratios) exhibiting variations in SPR peak positions (triangle, filled circle, and circle for $\mathrm{AR}=0.1,0.2$, and 0.3 , respectively) (a) and peak intensities (triangle, filled circle, and circle for $\mathrm{AR}=0.1,0.2$, and 0.3 , respectively) with the refractive index of a surrounding medium $(b)$

ratios, but of the same size in the same dielectric medium (cesium bromide). The variation in peak positions of the transverse and longitudinal modes w.r.t. the aspect ratio is shown in Fig. 2. As the aspect ratio increases, the transverse mode peak shows a red shift, while that of the longitudinal mode shows a blue shift. As expected, both peaks converge when the aspect ratio approaches unity (i.e., when cluster becomes spherical).

\subsection{Dependence on the surrounding medium}

The SPR peak position and intensity are strongly dependent on the refractive index of a dielectric matrix, in which metal nanoparticles are dispersed randomly. In fact, the resonance condition (or SPR peak position) is obtained, when the frequency-dependent metal dielectric constant is equal to the dielectric constant of a surrounding medium, which is usually constant. Mathematically, we say that the SPR peak is obtained, when $-\epsilon_{\text {metal }}(\omega)=\epsilon_{\text {media. }}$. Usually, the graphs of SPR peak positions are plotted with respect to the refractive index of a medium, since the dielectric constant of a medium $\left(\epsilon_{\mathrm{m}}\right)$ is related to its refractive index. The refractive indices of cesium chloride, cesium bromide, and cesium iodide are 1.6403, 1.69706, and 1.78718, respectively [23]. The data in Fig. 3, (triangle, filled circle, and circle for $\mathrm{AR}=0.1$, 0.2 , and 0.3 , respectively) are the experimental data

for cesium nanoparticles embedded in a cesium bromide matrix.

Hence, one can expect a variation in both peak positions and intensities of the SPR due to cesium nanorods of the same shape and size embedded in three different Cesium halides. Both the transverse mode SPR peak position and its intensity show a linear variation with increasing the refractive index of a surrounding medium (Fig. 3). The slope of this variation is expressed in $\mathrm{nm} / \mathrm{RIU}$ (Refractive Index Unit). A large slope would yield a large shift in the SPR peak position and a similar large increase in the intensity for a small change in the refractive index of the background. The nature of the curves clearly shows that the sensitivity to the background refractive index would depend on the shape of the metal nanoparticle, with sensitivity being maximum for spherical particles.

\section{Conclusion}

The optical absorption properties of cesium-cesium halide nanocomposite thin films are studied theoretically, by using Gans' model. The dependence of the surface plasmon resonance peak position and intensity on the cesium particle grain shape (aspect ratio of nanorods), and the surrounding medium $(\mathrm{CsCl}$, $\mathrm{CsBr}$, and $\mathrm{CsI}$ ) are investigated. The scattered experimental data are fitted well with the theoretical model results, by suggesting that Gans' model is adequate for a simple metal in dielectric systems. The continuous variation in the SPR peak position and intensity with the aspect ratio of cesium nanorods and the surrounding refractive index suggest that a good tunability can be achieved by controlling these parameters. Such knowledge will allow one to control the design and engineering of sensors and particle detectors based on SPR responses.

1. S. Asaka, M. Itoh, M. Kamada. Ultraviolet light amplification within a nanometer-sized layer. Phys. Rev. B 63, 081104(R) (2001).

2. M. Cremona, J.A.M. Perira, S. Pelli, G.C. Righini. Optical waveguides produced in $\mathrm{LiF}$ by $\mathrm{MeV}$ ion beam bombardment. Appl. Phys. Lett. 81, 4103 (2002).

3. H. Fujita, K. Yamauchi, A. Akasaka, H. Irie, S. Masunaga. Pressure dependence of direct band gap at $\Gamma$ point in solids. J. Phys. Soc. Japan 68, 1994 (1999).

4. P.V. Mitchell, D.A. Wiegand, R. Simoluchowski. Formation of F-centers in $\mathrm{KCl}$ by X-rays. Phys. Rev. 121, 484 (1961).

ISSN 2071-0194. Ukr. J. Phys. 2018. Vol. 63, No. 9 
5. B.R. Sever, N. Kristianpollar, F.C. Brown. F-center production in alkali halide crystals by monochromatic X-ray and ultraviolet radiation. Phys. Rev. B 34, 1257 (1986).

6. J.R. Maldonato, Z. Liu, D.H. Dowell, R.E. Kirby, Y. Sun, P. Pianetta, F. Pease. Electron sources utilizing thin $\mathrm{CsBr}$ coatings. Microelectronic Engineering 86, 529 (2009).

7. A. Buzulutskov, E. Shafer, A. Breskin, R. Chechik, M. Prager. The protection of $\mathrm{K}-\mathrm{Cs}-\mathrm{Sb}$ photocathodes with $\mathrm{CsBr}$ films. Nucl. Instr. and Meth. A 400, 173 (1997).

8. B.K. Singh, E. Shefer, A. Breskin, R. Chechik, N. Arraham. CsBr and CsI UV photocathodes: New results on quantum efficiency and aging. Instr. \& Meth. A 454, 364 (2000).

9. G. Yoshikawa, M. Kiguchi, K. Ueno, A. Saiki. Visible light photoemission and negative electron affinity of singlecrystalline CsCl thin films. Surf. Sci. 544, 220 (2003).

10. S. Tsuchiya, M. Green, R.R.A. Syms. Structural fabrication using cesium chloride island arrays as a resist in a fluorocarbon reactive ion etching plasma. Electrochem. Solid State Lett. 3 (1), 44 (2000).

11. K. Kumar, P. Arun. Defect diffusion assisted formation of cesium metal clusters in Cesium halide thin films. J. Taibah Univ. Sci. 111230 (2017).

12. K. Kumar, P. Arun, C.R. Kant, N.C. Mehra, L. Makinistian. E.A. Albanesi. Effect of residual stress on the optical properties of $\mathrm{CsCl}$ thin films. J. Phys. Chem. Sol. 71, 163 (2010).

13. K. Kumar, P. Arun, C.R. Kant, B.K. Juluri. Metal cluster's effect on the optical properties of cesium bromide thin films. Appl. Phys. Lett. 100, 243106 (2012).

14. K. Kumar, P. Arun, C.R. Kant, V. Mathew. The effect of cesium metal clusters on the optical properties of cesium iodide thin films. Appl. Phys. A 99, 305 (2010).

15. A.B. Scott, W.A. Smith. The thermal stability of F-centers in alkali halides. Phys. Rev. 83, 982 (1951).
16. V. Amendola, R. Pilot, M. Frasconi, O.M. Marago. M.A. Iati. Surface plasmon resonance in gold nanoparticles: a review. J. Phys.: Cond. Matter. 29, 20 (2017).

17. C.F. Bohren, D.R. Huffman. Absorption and Scattering of Light by Small Particles (Wiley, 1983) [ISBN: 9783527618156].

18. M. Hu, J. Chen, Z. Y. Li, L. Au, G.V. Hartland, X. Li, M. Arquez, Y. Xia. Chem. Gold nanostructures: engineering their plasmonic properties for biomedical applications. Soc. Rev. 35, 1084 (2006).

19. R. Gans. Über die form ultramikroskopischer silberteilchen. Ann. Phys. 47, 270 (1915).

20. R. Gans. Über die form ultramikroskopischer goldteilchen. Ann. Phys. 37, 881 (1912).

21. S. Link, M.A. El-Sayed. Size and temperature dependence of the plasmon absorption of colloidal gold nanoparticles. J. Phys. Chem. B 103, 4212 (1999).

22. N.V. Smith. Optical constants of rubidium and cesium from 0.5 to $4.0 \mathrm{eV}$. Phys. Rev. B 2, 2840 (1970).

23. E.D. Palik. Handbook of Optical Constants of Solids (Academic Press, 1985) [ISBN: 9780125444224].

Received 20.10.17

Калдіп Кумар, П. Арун

ПОВЕРХНЕВИЙ ПЛАЗМОННИЙ РЕЗОНАНС

ВІД ЕЛІПТИЧНИХ НАНОЧАСТИНОК ЦЕЗІЮ, ВБУДОВАНИХ У ТОНКІ ПЛІВКИ ГАЛІДУ ЦЕЗІЮ

$\mathrm{P}$ е $з$ ю м е

Вивчено піки абсорбції поверхневого плазмонного резонансу від нанострижнів цезію в галідах цезію (CsCl, CsBr i CsI). Розмір і форма цих нанострижнів змінюються з часом, що веде до труднощів порівняно з теорією. Гарну відповідність експерименту і теорії для нанокомпозитів Cs-галід цезію отримано в рамках моделі Р. Ганса. 